\title{
Cyclic plasticity and fatigue of metals
}

\author{
H. MUGHRABI \\ Institut für Werkstoffiwissenschaften, Lehrstuhl I, Universität Erlangen-Nürnberg, Martensstr. 5, \\ 91058 Erlangen, Germany
}

\begin{abstract}
This report ${ }^{*}$ ) is a survey of the cyclic deformation and fatigue behaviour of selected engineering steels and alloys. Emphasis is placed on the important roles of the cyclic slip mode and the stability of the microstructure during cyclic stressing and on the conditions of fatigue testing with respect to the failure mechanisms and fatigue life. The examples presented include low-temperature fatigue, high-temperature fatigue in the presence of dynamic strain ageing and thermomechanical fatigue.
\end{abstract}

\section{INTRODUCTION}

The cyclic deformation behaviour and the fatigue life of metallic materials depend critically on the stability of the microstructure during cyclic loading and on the cyclic slip mode both of which in turn, and depending on temperature and testing mode, govern the cyclic hardening/softening and the mode of fatigue crack initiation and propagation. Perhaps the most prominent example is the cyclic strain localization, softening and fatigue crack initiation in persistent slip bands in the case of age-hardened alloys containing shearable precipitates. In addition to metallurgical factors, the conditions and mode of cyclic stressing can play an important role.

In this paper, some results of more recent studies of the author and his research group on the fatigue of different engineering materials will be presented, cf. [1,2]. This work addresses low- and high-temperature push-pull fatigue including thermomechanical fatigue. Among the materials investigated are the age-hardenable aluminium alloy $\mathrm{AlZnMgCu} 0.5$ which is similar to the alloy 7022 [1,3], martensitic and bainitic variants of the roller bearing steel SAE 52100, German designation $100 \mathrm{Cr} 6[1,4,5]$, the metastable austenitic steels of the AISI $304 \mathrm{~L}-$-series, German designations $\mathrm{X} 3 \mathrm{CrNi} 189,[1,2,6,7,8]$ and $\mathrm{X} 2 \mathrm{CrNi} 1911[9,10,11]$, the normalized plain carbon steel SAE 1045, German designation $\mathrm{Ck} 45[2,12]$, and the monocrystalline $\gamma^{\prime}$-hardened nickel-base superalloy CMSX-6 [2,13].

\section{EXPERIMENTAL OBSERVATIONS AND DISCUSSION}

\section{Aluminium alloy $\mathrm{AlZnMgCu} 0.5[1,3]$}

It is remarkable that,in the solid-solution hardened state (as heat-treated), this alloy exhibits a marked cyclic hardening (in plastic-strain controlled tests) in combination with a short fatigue life, as compared with the behaviour of the alloy in the peak-aged condition (Fig. 1). The reason lies in the strong cyclic hardening due to the cyclic deformation-induced formation of numerous tiny precipitates and dislocation loops (Fig. 2). Hereby it is noteworthy that these defects extend right up to the grain boundaries and that fatigue cracks initiate mainly transgranularly, whereas peak-aged or overaged alloys usually exhibit precipitation-free zones at the grain boundaries (Fig. 3) which frequently cause intergranular fatigue crack initiation.

*)

Extended version of lecture presented at local conference "Gefuge und Bruch", Bochum, March 17-19, 1993. 
Roller bearing steel SAE $52100[4,5]$

This high-st rength steel, hardened martensitically or bainitically, exhibits very interesting fatigue properties, characterized by very limited ductility, a markedly non-linear elastic stress-strain behaviour, cyclic deformation-induced martensitic transformation of retained austenite and fatigue lives that obey neither a Manson-Coffin nor a Basquin type law in the usual sense. Because of lack of space the reader is referred to the original papers $[4,5]$.

Metastable austenitic stainless steels of type AISI 304L [6-11]

These steels exhibit interesting fatigue properties at both low and high temperatures. At low temperatures the cyclic deformation behaviour of these steels is characterized by the cyclic deformation-induced martensitic transformation (Fig. 4), combined with a very strong cyclic hardening. This behaviour is most pronounced at temperatures below room temperature and gives rise to a very marked strength enhancement when the fatigue test is performed at a temperature of about $200 \mathrm{~K}$ or lower (Fig. 5). This strengthening effect which can be exploited technologically can be related directly to the martensite content $[10,11]$. Hereby, it is convenient that the martensite content can be controlled by suitable choice of plastic strain amplitude, number of cycles and temperature. In order to optimize the strength properties for technical applications, the residual fatigue life after (low-temperature) pre-fatigue with the aim to enhance the strength by fatigue-induced martensitic transformation is also of interest. In this case, it is found that an intermediate martensite content is optimal (Fig. 6).

At higher temperatures the cyclic deformation behaviour is influenced strongly by dynamic strain ageing effects which are most pronounced at temperatures around $450^{\circ} \mathrm{C}[7,8]$. In plastic-strain controlled tests this leads to a maximum of the attained maximum/saturation stress amplitude as a function of testing temperature in the temperature range around $450^{\circ} \mathrm{C}$ (Fig. 7) It is interesting to note that while the cyclic slip mode is wavy at lower and at higher temperatures, it is planar in the temperature range of dynamic strain ageing (Fig. 8). The reason for this behaviour seems to lie mainly in the formation of small coherent carbides which are cut by the dislocations, accompanied by the formation of planar slip bands (Fig. 9). When the planarity of slip is very pronounced as in the case of an AISI 316L steel [14], fatigue life can be enhanced to the extent that it becomes maximal in the temperature range of dynamic strain ageing inspite of the increased stress amplitude.

Normalized plain carbon steel SAE 1045 [12]

This steel also exhibits the phenomenon of dynamic strain ageing during fatigue at higher temperatures with a maximal effect at about $300^{\circ} \mathrm{C}$. A wavy cyclic slip mode prevails at all temperatures. In the temperature range of dynamic strain ageing, the dislocation arrangement consists of dense dislocation walls, whereas at lower and higher temperatures dislocation cell and subgrain structures are observed, respectively (Fig. 10). The temperature dependence of fatigue life depends in an interesting manner on the mode of testing (Fig. 11). Thus, in stress-controlled tests, enhanced cyclic hardening in the temperature range of dynamic strain ageing leads to a decrease of the plastic strain amplitude and hence to a maximum of fatigue life. On the other hand in plastic -strain controlled tests, the stress amplitude is maximal in the temperature range of dynamic strain ageing and, as a consequence, the fatigue life exhibits a minimum.

\section{Monocrystalline nickel-base superalloy CMSX-6, near [001]-orientation [13]}

In the case of this $\gamma$-hardened turbine blade material the thermomechanical fatigue (TMF) behaviour is of particular interest. TMF tests were performed for different temperature-total strain cycles with a lower temperature of $600^{\circ} \mathrm{C}$ and an upper temperature of $1100^{\circ} \mathrm{C}$ (Fig. 12). It was found that fatigue life correlated inversely with the tensile stress amplitude (Fig. 13) and is hence smallest for out-of-phase temperature-strain cycles for which the tensile stress amplitude is largest. Fatigue fracture invariably occurred in a crystallographically facetted shear mode which is considered typical of fatigue failure (Fig. 14) and showed little effect of creep damage. Hereby, cyclic strain localisation, related to coarsening of the $\gamma$ structure played a more or less important role. In all cases, a coarsening of the $\gamma$ structure could be observed, sometimes accompanied by the formation of small secondary $\gamma^{\prime}$ precipitates (Fig. 15). A particularly noteworthy feature is the directional $\gamma^{\prime}$ coarsening which was found to be most pronounced in out-of-phase tests and which occurred in such a manner that soft $\gamma$-channels formed, inclined under an angle to the stress axis, thus promoting cyclic shear localization. 


\section{ACKNOWLEDGMENTS}

The author acknowledges gratefully the contributions of the members of his research group over the years and the financial support of Deutsche Forschungsgemeinschaft and Volkswagenstiftung. Sincere thanks also go to Frau G. Raffel and Frau W. Teichmann for their help in the preparation of the manuscript.

\section{REFERENCES}

1) MUGHRABI H.: Fatigue of engineering materials. In: Proc. of the 10th Ris $\emptyset$ Int. Symp. on Metallurgy and Materials Science: Materials Architecture, eds. J.B. Bilde-Sørensen et al., Ris $\emptyset$ National Laboratory, Roskilde, 1989, p. 191.

2) CHRIST H.J. and MUGHRABI H.: Microst ructure and low-cycle fatigue. In: Proc. of Third. Int. Conf. on Low Cycle Fatigue and Elasto-Plastic Behaviour of Materials, Berlin, Sept. 1992, edited by K.-T. Rie et al., Elsevier Applied Science, London and New York, p. 56.

3) CHRIST H.J., LADES K., VÖLKL L. and MUGHRABI H.: The role of microstructural processes in the application of the incremental step test to determine the cyclic stress-strain curve of an aluminium alloy. In: Proc. of Third Int. Conf. on Low Cycle Fatigue and Elasto-Plastic Behaviour of Materials, Berlin, Sept. 1992, edited by K.-T. Rie et al., Elsevier Applied Science, London and New York, p. 100.

4) SOMMER C., CHRIST H.J. and MUGHRABI H.: Non-linear elastic behaviour of the roller bearing steel SAE 52100 during cyclic loading, Acta metall. mater. 39, 1177 (1991).

5) CHRISTT H.J., SOMMER C., MUGHRABI H., VOSKAMP A., BESWICK J. and HENGERER F.: Fatigue behaviour of three variants of the roller bearing steel SAE 52100. Fatigue Fract. Engng. Mater. Struct. 15, 855 (1992).

6) BAYERLEIN M., CHRIST H.-J. and MUGHRABI H: Plasticity-induced martensitic transformation during cyclic deformation of AISI 304L stainless steel, Mat. Sci. Eng. A 114, L11 (1989).

7) PETRY F., CHRIST H.J. and MUGHRABI H.: Cyclic deformation of the stainless steel AISI 304L as a function of temperature. In: Microstructure and Mechanical Properties of Materials, Proc. of a DGM Symposium, Bad Nauheim 1990. DGM Informationsgesellschaft, Oberursel, 1991, p. 79. And: unpublished work of F. Petry, Doctorate Thesis, Universität Erlangen-Nürnberg, 1989.

8) ZAUTER R., PETRY F., BAYERLEIN M., SOMMER C., CHRIST H.-J. and MUGHRABI H.: Electron channeling contrast as a supplementary tool for microstructural investigations in deformed metals. Phil. Mag. A 66, 425 (1992).

9) BAYERLEIN M., MUGHRABI H., KESTEN M. and MEIER B.: Inprovement of the strength of a metastable austenitic stainless steel by cyclic deformation-induced martensitic transformation at $103 \mathrm{~K}$. Mat. Sci. Eng. A 159, 35 (1992).

10) MAIER H.J., DONTH B., BAYERLEIN M. and MUGHRABI H.: Strength enhancement of $304 \mathrm{~L}$ stainless steel by fatigue-induced low-temperature martensitic transformation. In: FATIGUE 93, Proc. of the Fifth Int. Conf., edited by J.P. Bailon and J.I. Dickson, Vol. I, EMAS Ltd., U.K., p. 85.

11) MAIER H.J., DONTH B., BAYERLEIN M., MUGHRABI H., MEIER B. und KESTEN M.: Optimierte Festigkeitssteigerung eines metastabilen austenitischen Stahles durch wechselverformungsinduzierte Martensitumwandlung bei tiefen Temperaturen. Submitted to $Z$. Metallkde.

12) WEISSE M., WAMUKWAMBA C.K., CHRIST H.J. and MUGHRABI H.: The cyclic deformation and fatigue behaviour of the low carbon steel SAE 1045 in the temperature range of dynamic strain ageing. Acta metallurgica et materialia, in print.

13) KRAFT S., ZAUTER R. and MUGHRABI H.: Aspects of high-temperature low-cycle thermomechanical fatigue of a single crystal nickel-base superalloy. Fatigue Fract. Engng. Mater. Struct. 16, 237 (1993).

14) GERLAND M., MENDEZ J., LÉPINOUX J. and VIOLAN P.: Dislocation structure associated with corduroy contrast in a $316 \mathrm{~L}$ alloy fatigued at $0.3-0.5 \mathrm{~T}_{\mathrm{m}}$. In: Proc. of Int. Conf. on Fundamental Aspects of Dislocation Interactions, Ascona, Switzerland, 1992. To appear in Mat. Sci. Eng. A. 


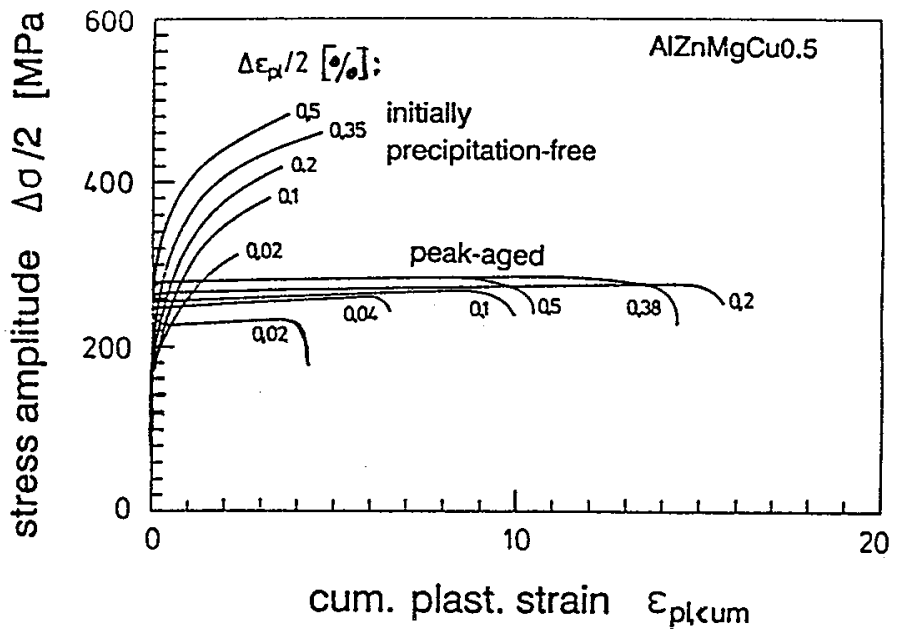

Fig. 1: Cyclic hardening curves of the aluminium alloy $\mathrm{AlZnMgCu} 0.5$ in the initially precipitation-free, solid-solution hardened, and in the peak-aged states $[1,3] . \Delta \epsilon_{\mathrm{pl}} / 2$ : plastic strain amplitude, $\Delta \sigma / 2$ : stress amplitude.
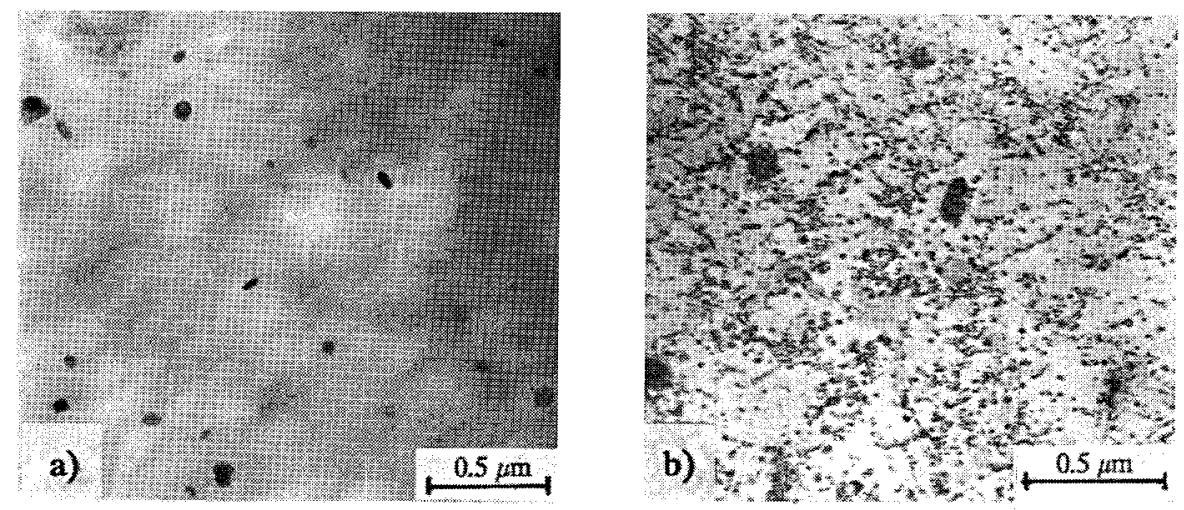

Fig. 2: Transmission electron microscopy (TEM) observations on the aluminium alloy AlZnMgCu $0.5[1,3]$. a) Solid-solution hardened state. b) Solid-solution hardened state, after fatigue at $\Delta \epsilon_{\mathrm{pl}}=4 \cdot 10^{-4}, 293 \mathrm{~K}$. 

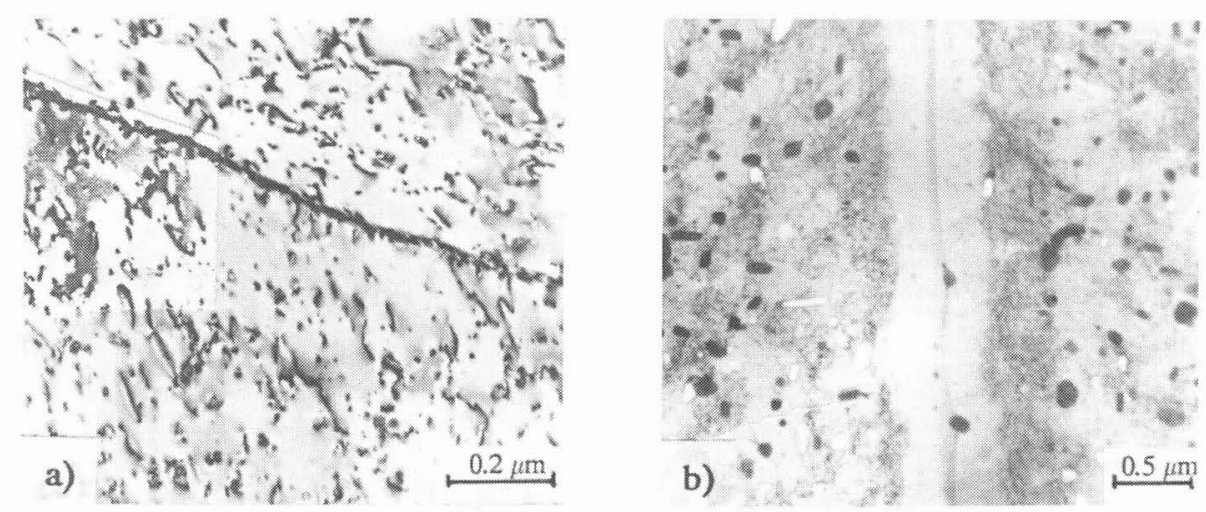

Fig. 3: TEM micrographs of the aluminium alloy $\mathrm{AlZnMgCu} 0.5$ after fatigue at $293 \mathrm{~K}[1,3]$. a) Solid-solution hardened state. b) Overaged state.
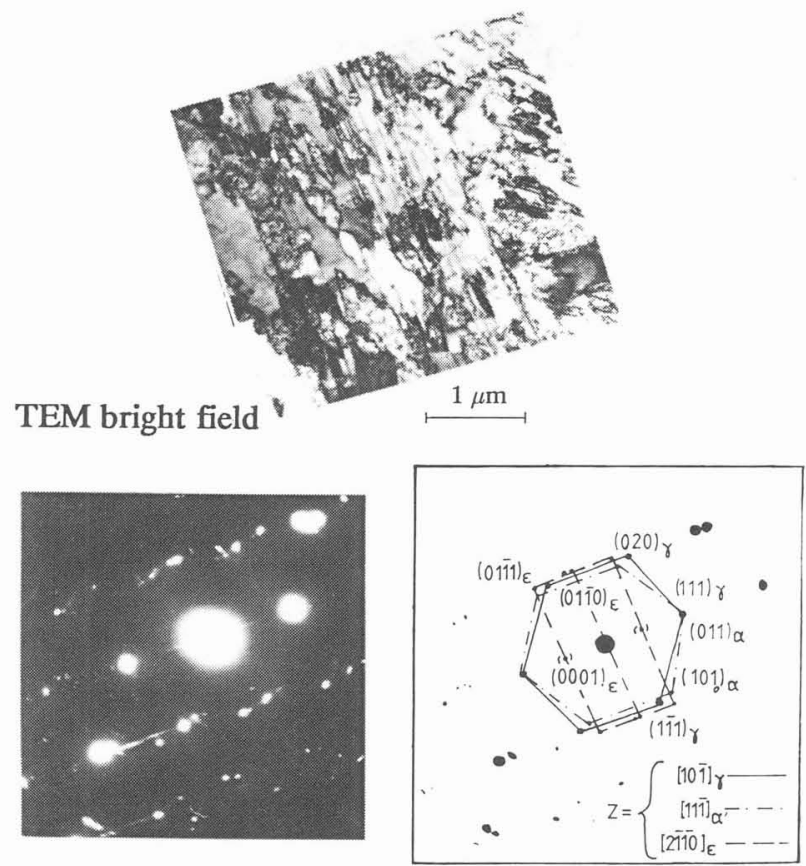

TEM diffraction

Fig. 4: TEM evidence of cyclic plasticity-induced martensite formation in the stainless steel $\mathrm{X} 3 \mathrm{CrNi} 189$ after room-temperature fatigue at $\Delta \epsilon_{\mathrm{pl}}=1 \%[7]$. 


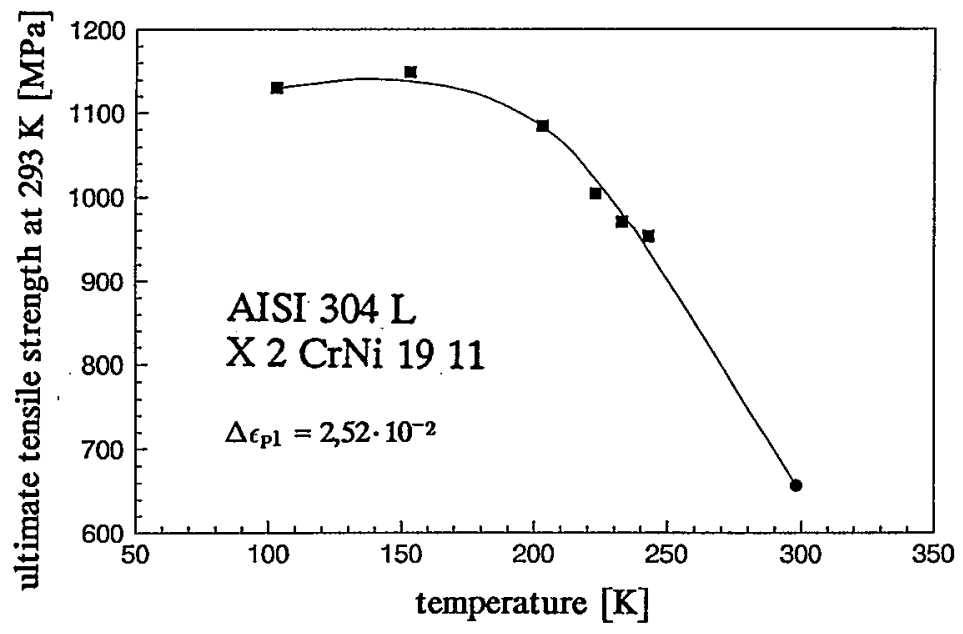

Fig. 5: Ultimate tensile strength of the austenitic stainless steel X $2 \mathrm{CrNi} 1911$, measured at room temperature, after maximum fatigue-induced martensitic transformation at lower temperatures at $\Delta \epsilon_{\mathrm{pl}}=2.52 \cdot 10^{-2}[10,11]$.

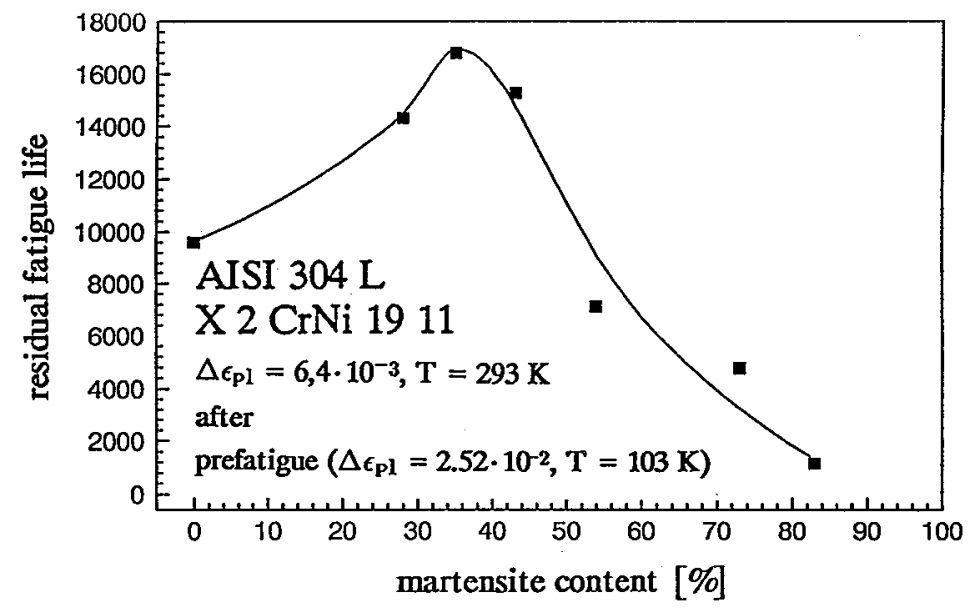

Fig. 6: Residual fatigue life after fatigue at $\Delta \epsilon_{\mathrm{pl}}=6.4 \cdot 10^{-3}, \mathrm{~T}=293 \mathrm{~K}$, as a function of martensite content introduced by pre-fatigue $\left(\Delta \epsilon_{\mathrm{pl}}=2.52 \cdot 10^{-2}, \mathrm{~T}=103 \mathrm{~K}\right)$ to different numbers of cycles [11]. 


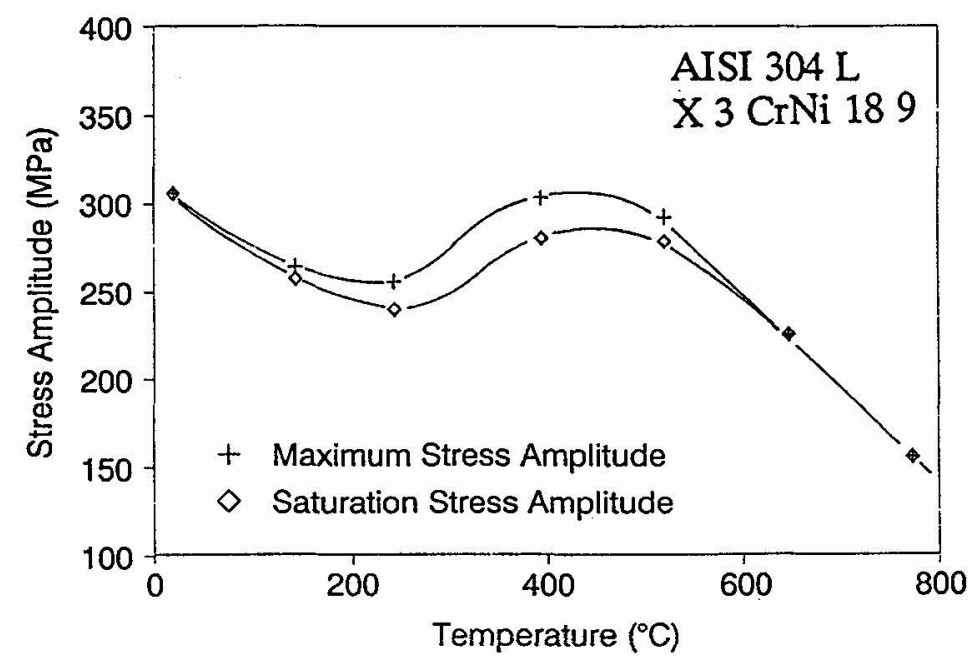

Fig. 7: Dependence of the maximum and/or saturation stress amplitudes of the austenitic steel $\mathrm{X} 3 \mathrm{CrNi} 189$ after fatigue at $\Delta \epsilon_{\mathrm{pl}}=1 \%$ on the temperature of fatigue $[7,8]$.
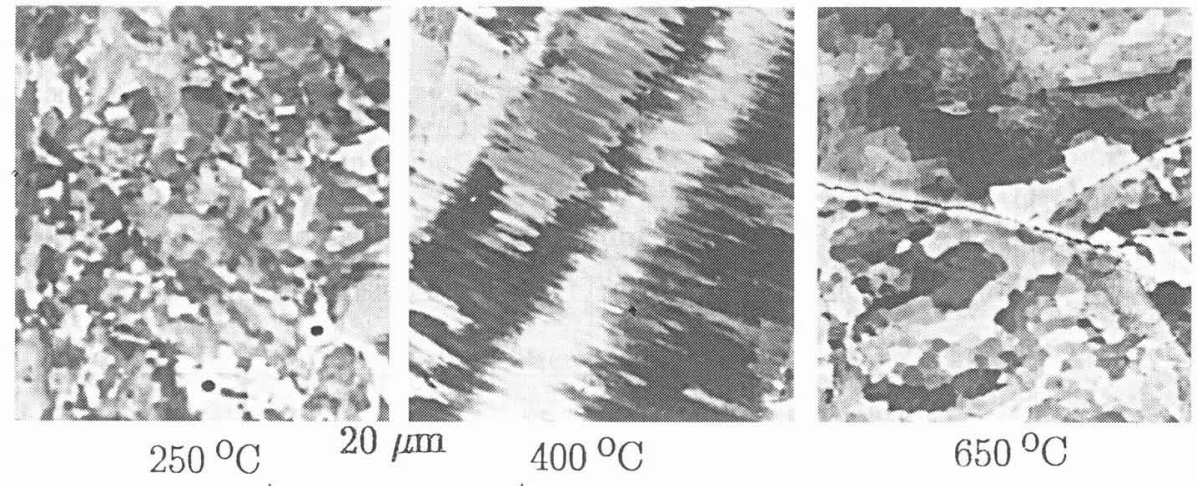

Fig. 8: Scanning electron microscopy (SEM) micrographs of dislocation substructures in the austenitic stainless steel $\mathrm{X} 3 \mathrm{CrNi} 189$ after fatigue $\left(\Delta \epsilon_{\mathrm{pl}}=1 \%\right)$ ) at $250^{\circ} \mathrm{C}, 400^{\circ} \mathrm{C}$ and $650^{\circ} \mathrm{C}[8]$. Electron channeling contrast. Longitudinal sections. 
a)

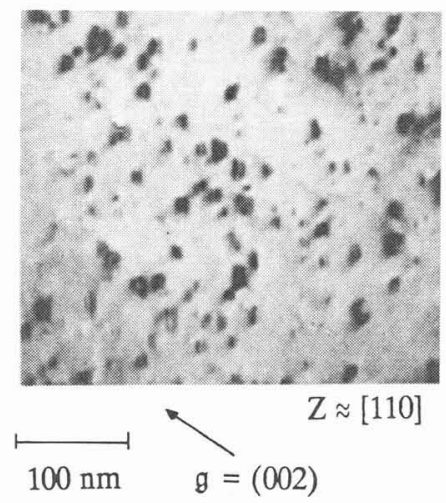

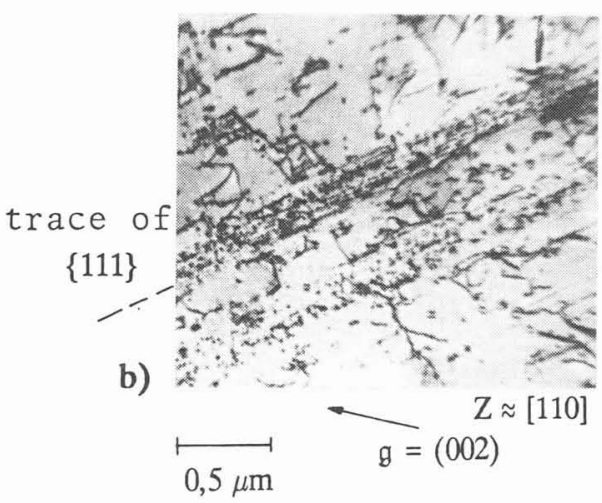

Fig. 9: TEM micrographs of the austenitic stainless steel $\mathrm{X} 3 \mathrm{CrNi} 189$ after fatigue at $\Delta \epsilon_{\mathrm{pl}}=1 \%, \mathrm{~T}=400^{\circ} \mathrm{C}[7]$. a) Cut small carbides. b) Planar glide band. Longitudinal section.

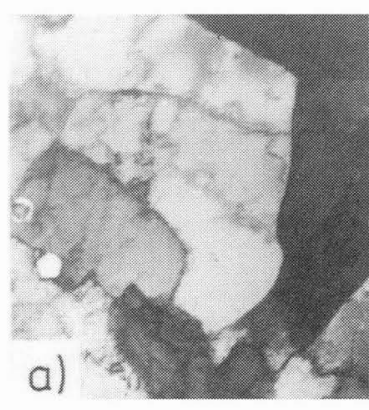

$20^{\circ} \mathrm{C}$

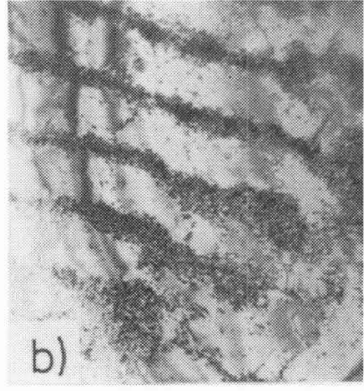

$265^{\circ} \mathrm{C}$

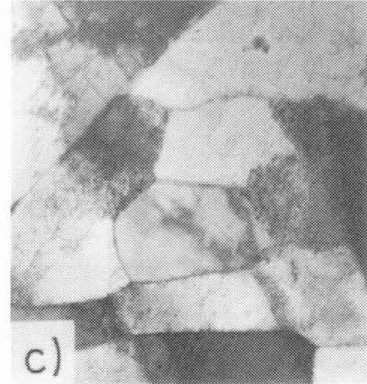

$375^{\circ} \mathrm{C}$

Fig. 10: TEM micrographs of the plain carbon steel SAE 1045 after stress-controlled fatigue at $\Delta \sigma / 2=400 \mathrm{MPa}$ [12]. a) $20^{\circ} \mathrm{C}$, b) $265^{\circ} \mathrm{C}$, c) $375^{\circ} \mathrm{C}$. Longitudinal sections.

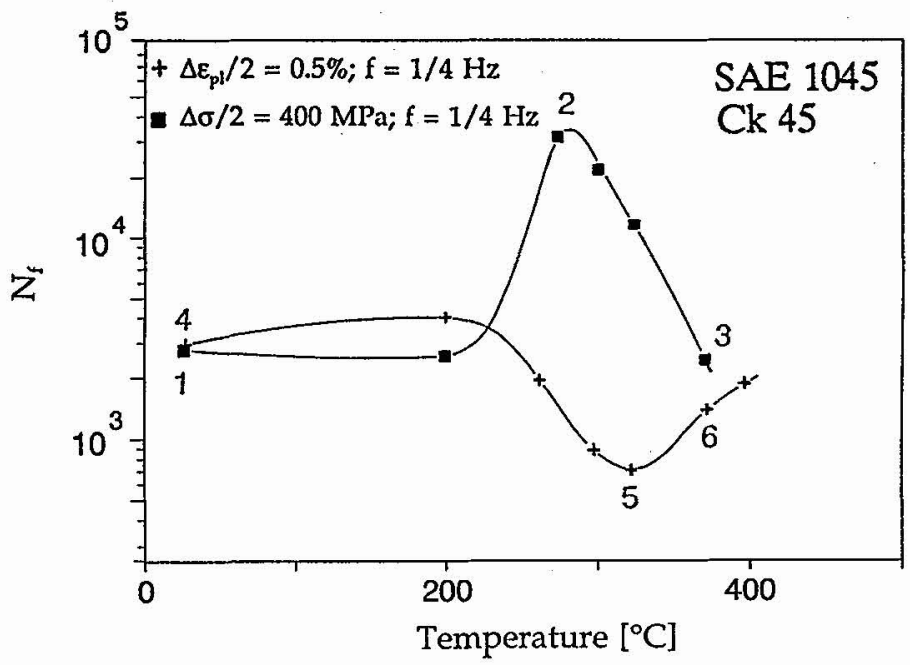

Fig. 11: Number of cycles to failure, $N_{f}$, of plain carbon steel SAE 1045 as a function of temperature of fatigue for stress- and plastic-strain controlled fatigue [12]. 


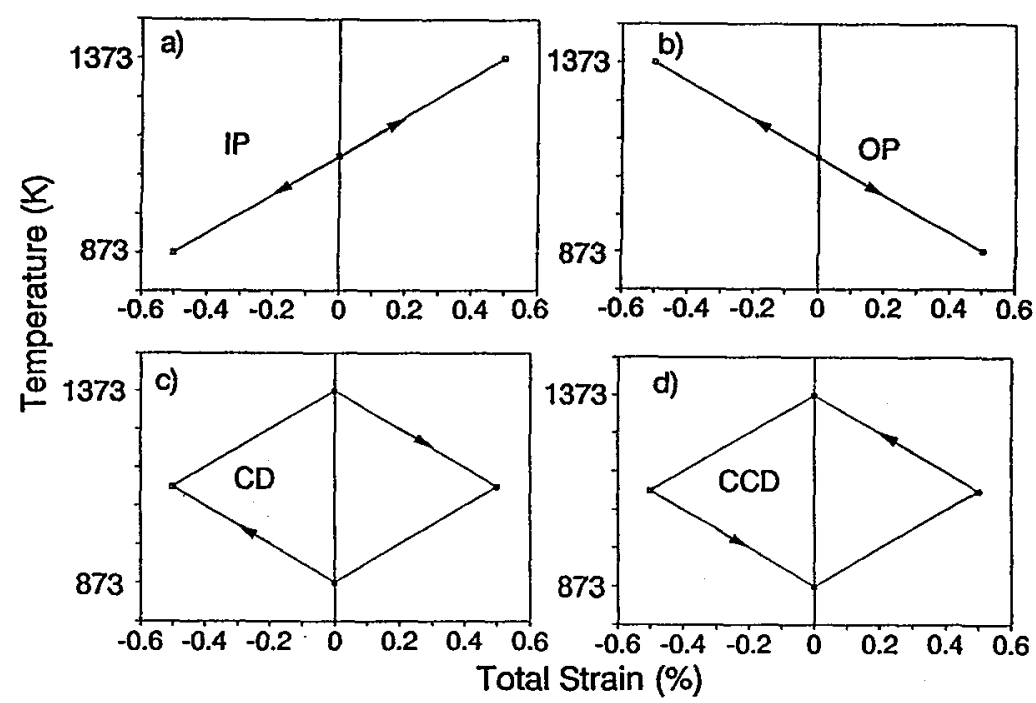

Fig. 12: Temperature-total strain cycles applied in the TMF study of the monocrystalline nickel-base superalloy CMSX-6 [13]. a) In-phase (IP), b) out-of-phase (OP), c) Clockwise diamond (CD), d) Counter-clockwise diamond (CCD).

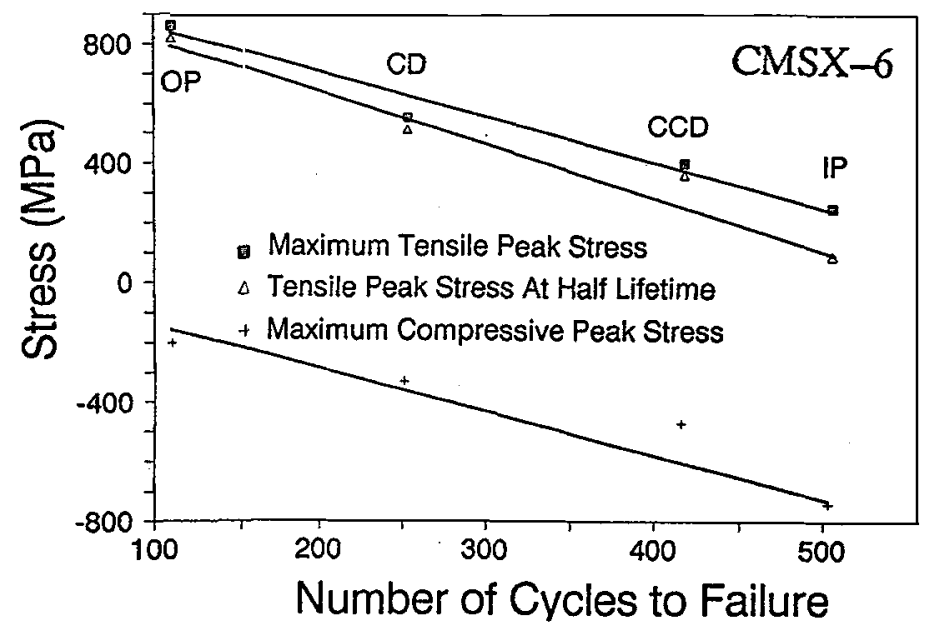

Fig. 13: Dependence of the numbers of cycles to failure on the stress amplitudes attained in TMF (OP, IP, CD, CCD) of the monocrystalline nickel-base superalloy CMSX 6 [13]. 

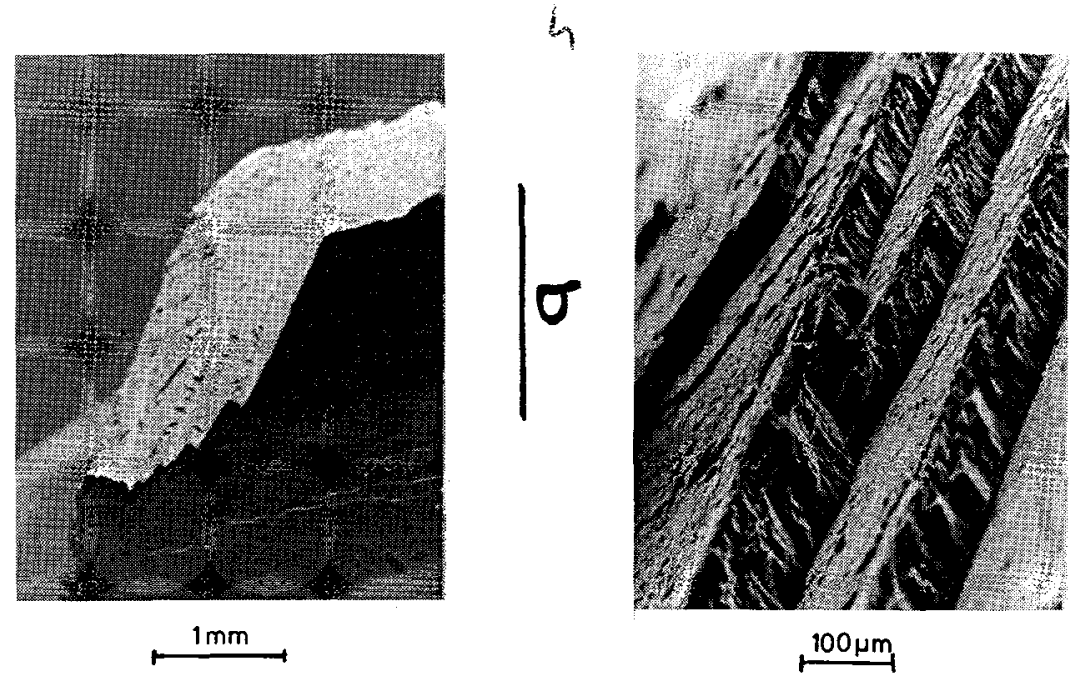

Fig. 14: Fatigue fracture surface (SEM) of monocrystalline nickel-base superalloy CMSX-6 specimen after out-of-phase TMF [13]. Stress axis vertical.
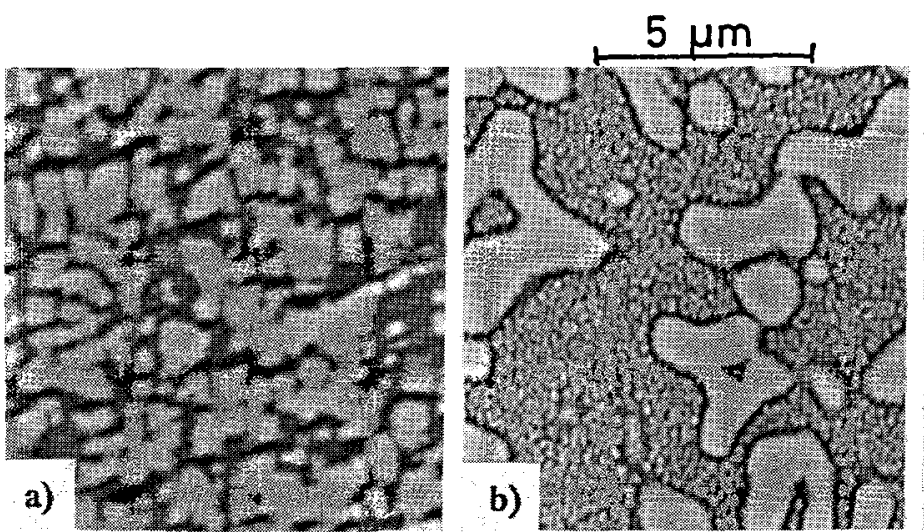

\section{cyclic strain localization}

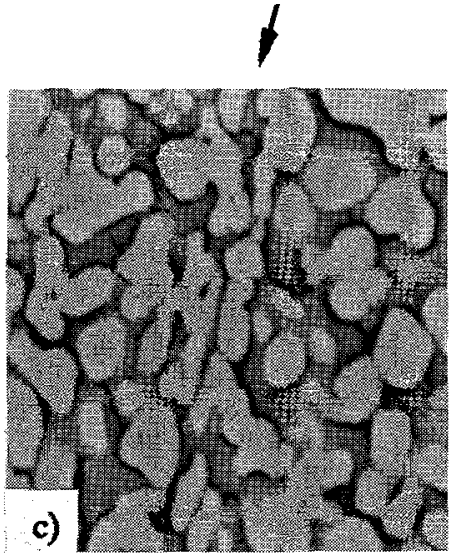

Fig. 15: SEM micrographs of the $\gamma$ particle morphology of monocrystalline CMSX-6 specimens [13]. Longitudinal sections. a) initial state, b) after $C D$ thermomechanical fatigue, c) after OP thermomechanical fatigue. 